\title{
Falso fungus ball simulando litiasis vesical
}

\author{
J. Arce Gil, J. Pascual García, V. Monllau, F. Dalet, F. Millán Rodríguez, H. Villavicencio Mavrich \\ Servicio de Urología. Unidad de Litiasis. Fundació Puigvert. Barcelona.
}

Actas Urol Esp 2006; 30 (3): 343

$\mathrm{P}$ aciente varón de 42 años de edad afecto de parálisis cerebral infantil como único antecedente de interés, portador de sonda vesical permanente por vejiga neurógena hipotónica y disinergia vesico-esfinteriana, es remitido a nuestro centro para realización de litotricia extracorpórea sobre litiasis vesical diagnosticada por ecografía.

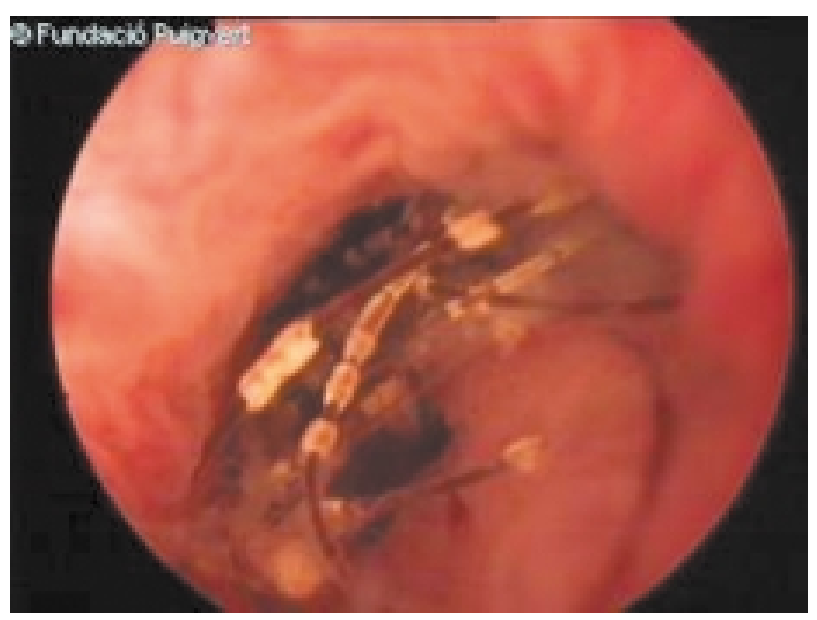

FIGURA 2. Estructura fibrilar en uretra prostática

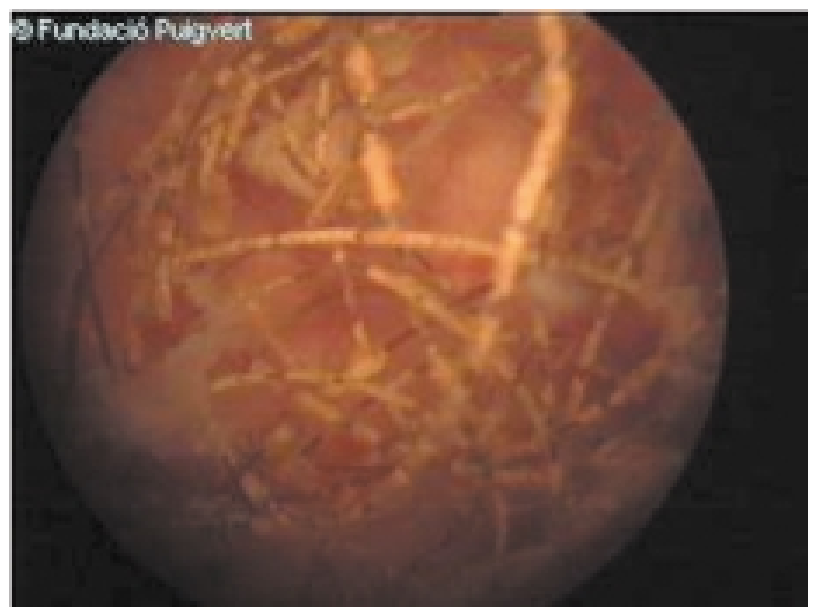

FIGURA 1. Estructura fibrilar en forma de ovillo con restos de calcificación superficial.
Se realiza cistoscopia que demuestra estructura fibrilar redondeada en forma de ovillo con restos de calcificación en superficie. (Figs. 1 y 2). Orientada inicialmente como fungus ball y descartado por interrogatorio la posibilidad de cuerpo extraño, se realizaron cultivos que fueron persistentemente positivos a Escherichia Coli, Enterococcus Faecalis y Pseudomonas Aeuroginosa sin aislamiento de hongos. Tras valoración de estudios de imagen y hallazgos microbiológicos se orientó la imagen como moco vesical en forma deshidratada con calcificación superficial secundaria a gérmenes ureolíticos.

\section{REFERENCIAS}

1. Rao AR, Hussein A, Motiwala H. Trichobezoar of urinary bladder with secondary calculus: case report. J Endourol 2004 Jun; 18(5):493-494.

2. Comite CV, Mc Donald M, Minton J, Yalla SV. Fungal bezoar and bladder ruptura secondary to candida tropicales. Urology. 1996 Mar;47(3):439-441.

3. Morton KM, Robertson AJ, McIntyre J. Urinary bladder fungus ball.J Clin Pathol. 1988 Nov;41(11):1243-1244.

4. Favazza T, Midha M, Martin J, Grob BM. Factors influencing bladder stone formation in patients with spinal cord injury. J Spinal Cord Med. 2004;27(3):252-254.

5. Ord J, Lunn D, Reynard J. Bladder management and risk of bladder stone formation in spinal cord injured patients. J Urol 2003 Nov;170(5):1734-1737.

6. Millán Rodríguez F, Tornero Ruiz J, López Llaurado H, Rousaud Barón F, Marti Malet J, Izquierdo Latorre F, Rousaud Barón A. Treatment of bladder lithiasis with shock-wave extracorporeal lithotripsy. Actas Urol Esp 2001 Jul-Aug; 25(7):504-509.

7. Sylla C, Fall PA, Ndoye A, Diao AB, Gueye SM, Diagne BA. Bladder lithiasis.Dakar Med 2001;46(1):29-31.

Dr. J. Arce Gil

E-mail: Jacobo1976@hotmail.com

(Trabajo recibido el 27 de mayo 2005) 